\title{
Immune modulation of the brain-gut-microbe axis
}

\author{
Sahar El Aidy ${ }^{1,2 *}$, Timothy G. Dinan ${ }^{1,3}$ and John F. Cryan ${ }^{1,4}$ \\ ${ }^{1}$ Laboratory of Neurogastroenterology, Alimentary Pharmabiotic Centre, University College Cork, Cork, Ireland \\ ${ }^{2}$ Department of Industrial Biotechnology, Genetic Engineering and Biotechnology Research Institute, Sadat City University, Sadat City, Egypt \\ ${ }^{3}$ Department of Psychiatry, University College Cork, Cork, Ireland \\ ${ }^{4}$ Department of Anatomy and Neuroscience, University College Cork, Cork, Ireland \\ ${ }^{*}$ Correspondence: s.elaidy@ucc.ie \\ Edited and reviewed by: \\ Anton G. Kutikhin, Research Institute for Complex Issues of Cardiovascular Diseases under the Siberian Branch of the Russian Academy of Medical \\ Sciences, Russia
}

Keywords: neuropeptides, immune cells, gut microbiota, nervous system, HPA

Only recently have we fully appreciated that the classically separated domains of neurology, endocrinology, immunology and microbiology, with their various organs- the brain, glands, gut, immune cells and microbiota, could actually be joined to each other in a multidirectional network of communication, in order to maintain homeostasis. For example, local and systemic immune activation have profound neural and behavioral effects (Campos-Rodríguez et al., 2013), neuroendocrine hormones regulate immune cytokines, and together, the nervous system and immune system work together in synergy to protect the body from infection (Steinman, 2004). Analogously, the gut microbes greatly impact the host immunological, psychological, and overall well-being of the host (Collins and Bercik, 2013; El Aidy and Kleerebezem, 2013a; Wang and Kasper, 2013; Moloney et al., 2014). However, definitive mechanisms that orchestrate a functionally relevant communication within this network, in particular, during the early life development, are yet to be elucidated. A potential unifying mechanism very likely involves multiple-functioning molecules and their receptors, as they are produced by, act upon and move from one system to another linking the brain, gut, immune system, and microbiota. These messenger molecules include (among others) neurotransmitters, neuropeptides, endocrine hormones, and cytokines.

The physiological phenomenon of maturation of the immune and neurological systems, as well as the microbial colonization, initiated within the fetal period, are dynamic in their character and are expanding in time through the first months and even years of human's life. The mode of delivery, be it vaginal birth or caesarean-section, has recently been shown to be critical in determining the pioneer microbial composition of neonates (Dominguez-Bello et al., 2010). Particularly over the first few years of life, as the microbiota develops, there is a greater potential for disruption of the long-term microbial state upon the repeated use of antibiotics (Lemon et al., 2012). Not only does the antibiotics use disrupt the microbial community in healthy infants but also it amplifies the microbial dysbiosis in pediatric patients with Crohn's disease (Gevers et al., 2014). Several reports have shown that dysbiosis alone as may result from antibiotic treatment is sufficient to drive intestinal inflammation (Hooper et al., 2012). Additionally, alterations of the microbial composition are often associated with changes in brain development and plasticity and alterations in motor, anxiety and social behavior (Sudo et al., 2004; Diaz-Heijtz et al., 2011; Neufeld et al., 2011; Clarke et al., 2013; Desbonnet et al., 2014). Consequently, abrupt shifts during the infant's unique developmental path through this early unstable phase may have longer term health implications (Costello et al., 2012). Activation of the (innate) immune response during the primary colonization involves the induction of toll-like receptors (TLRs) (Carvalho et al., 2012; El Aidy et al., 2012a, 2013b) and is linked to the stress induced by colonization, which increases gut permeability (Dinan and Cryan, 2012) to the colonizing microbes and their metabolites. Although very crucial in the recognition of the gut microbes, the scenario of immune activation via TLRs appear not to respond promptly at the initial stage of colonization (El Aidy et al., 2013c), suggesting that the very rapid actions of neurotransmitters and hormones might be important to control the priming and migration of cells of the first line of defense. Several members of pioneer gut colonizers are able to produce neurotransmitters. Escherichia and Streptococcus, for instance, can produce norepinephrine and serotonin (5-HT), whereas, Lactobacillus and Bifidobacterium can produce GABA and acetylcholine (Roshchina, 2010; Lyte, 2011). Mobile cells of the immune system express receptors for neurotransmitters (Pert et al., 1985). For example, migration of immature dendritic cells (DCs) to lymph nodes is mediated via $\alpha 1$ adrenergic receptors (Maestroni, 2000), emphasizing the early effects of the sympathetic nervous system (SNS) at the start of a local immune response. Norepinephrine, a neurotransmitter of the SNS (among other molecules stored in sympathetic vesicles), has pro-inflammatory effects at low concentration mediated through binding to $\alpha 2$ adrenoceptors and reduction of cAMP levels (Spengler et al., 1990). On the other hand, acetylcholine, the principle vagal neurotransmitter, attenuates the release of cytokines [tumor necrosis factor-alpha (TNF- $\alpha$ ), interleukin (Il)-1 $\beta$, Il-6 and Il-18, but not the anti-inflammatory cytokine Il-10, in lipopolysaccharides (LPS) stimulated human macrophage cultures (Borovikova et al., 2000)]. Moreover, choline acetyltransferase (ChAT), the key enzyme in the synthesis of acetylcholine, is expressed by B cells, DCs, and macrophages in the mucosal-associated lymphoid tissue (MALT). Reardon et al. 
reported that ChAT expression begins after microbial colonization, following birth, and requires MyD88-dependent signaling derived from the intestinal microbiota (Reardon et al., 2013). Monocytes such as macrophages and other leucocytes travel through the blood and when they come within scenting distance of a given neurotransmitter, they begin to chemotaxically orient toward it, and then communicate with other immune cells in the adaptive arm such as $\mathrm{B}$ and $\mathrm{T}$ lymphocytes to ensure well-coordinated immune response.

In parallel, activation of the nervous system, such as afferent vagus nerve fibers by cytokines stimulates neuronal anti-inflammatory responses (Sternberg, 1997). Immune cells can produce various neurotransmitters and other factors, which alert the brain to the changes that occur in the body and affect the plasticity of the local and central nervous systems, thereby can regulate mood and behavior. Leukocytes, for example, synthesize and release corticotropin (ACTH) and endorphins in response to bacterial LPS (Harbour-McMenamin et al., 1985). Mounting an innate immune response during pathogenesis and transiently, during primary gut colonization results in the production of pro-inflammatory cytokines such as Il-1 $\beta$, TNF- $\alpha$, and IFN- $\gamma$ (El Aidy et al., 2013c). The proinflammatory cytokine- Il- $1 \beta$, for instance, is able to inhibit the release of norepinephine from noradrenoceptor axon terminals, in the intestine via the induction of nitric oxide (Rühl et al., 1994; Rühl and Collins, 1997). To note, norepinephrine via $\beta$ adrenergic signaling, inhibits many aspects of the innate and Th1 mediated immune response (Straub et al., 2006), whereas activated macrophages and other innate immune cells produce nerve repellent factors directed toward sympathetic nerve to counteract the sympathetic inhibitory effect (Miller et al., 2004). Importantly, another possible mechanism underlying the reduced levels of norepinephrine during mounting innate and Th1 mediated immune responses is the decreased LDOPA decarboxylase activity-the enzyme that converts L-DOPA to norepinephrine, as observed in both inflamed and noninflamed colonic mucosa of Crohn's patients (Magro et al., 2002).
One mechanism through which immune activation or immunomodulation may affect physiology and behavior is via actions on serotonergic systems (Lowry et al., 2007). Analogous to the action of gut microbiota during primary colonization, Lowry et al. found that the nonpathogenic Mycobacterium vaccae led to stimulation of the peripheral immune system. The Th1 and Treg but not Th2 mediated immune activation stimulated a specific subset of serotonergic neurons in the dorsal raphe nucleus of mice and increased serotonin metabolism within the ventromedial prefrontal cortex (Lowry et al., 2007). This finding demonstrates that the type of peripheral immune response is important in determining the effects on serotonergic neurons. Additionally, the study of Lowry and co-workers suggests that the immune-responsive subpopulation of serotonergic neurons in the dorsal raphe appears to play an important role in the regulation of mood during the health state. Afferent fibers within the vagus nerve could be involved in transferring signals of peripheral immune activation to the CNS (Maier et al., 1998). The regulating mechanism appears to involve enhancement of c-Fos expression in dorsal raphe nucleus serotonergic neurons (Hollis et al., 2006). It is therefore tempting to speculate that immune activation under physiological conditions stimulates a subset of serotonergic neurons, distinct from those activated under pathological conditions or by uncontrollable stressors. Nevertheless it is unclear if this association reflects a causal or reactionary response. Immune activation induces symptoms of depression and anxiety in human patients including disorders such as irritable bowel syndrome (IBS), a disorder of the gut-brain axis (Clarke et al., 2009) and in patients receiving treatment with interferon (Felger et al., 2013). Treatment with serotonergic antidepressant drugs prevents the onset of depressive symptoms in such situations (Capuron and Miller, 2004; Capuron et al., 2004). Moreover, recent data has shown that the TNF antagonist infliximab reduces depression symptoms in a subset of patients with high baseline inflammatory biomarkers (Raison et al., 2013). Of note, local and systemic depletion of the 5-HT precursor- Tryptophan (Trp) is associated with elevation of the immunomodulatory enzyme Indoleamine-pyrrole 2,3-dioxygenase (IDO), which occurs during immune activation (Moffett and Namboodiri, 2003) and transiently during primary gut colonization (El Aidy et al., 2012b, 2013b). Moreover, 5-HT is altered by the gut microbiota, being elevated in conventionally raised mice, only when gut colonization occurs at birth (Clarke et al., 2013). Collectively, these findings illustrate evidence that serotonergic systems may play an important role in the relationship between the immune function, gut microbiota, and psychological state.

Local and systemic elevation of proinflammatory cytokines, in particular, Il$1 \beta$ and Il-6 and altered 5-HT levels cause activation of the hypothalamicpituitary-adrenal (HPA) axis and production of corticotrophin releasing factor (CRF). CRF, which is also elevated in stress response, causes disturbance to other neuropeptides, leading to changes in mood and behavior (Dinan and Cryan, 2012). CRF stimulates the anterior pituitary gland to release the stress hormone; ACTH, which in turn stimulates release of cortisol from the adrenal gland. Cortisol, through a feedback loop, regulates the levels of CRF, and ACTH. Importantly, immune cells, through the COX-2 pathway and production of PEG2 during (pro-) inflammation, stimulate the adrenal gland to produce corticosterone, which exclusively supports the $\beta$ adrenergic pathway through which the SNS perform its anti-inflammatory effect (Straub et al., 2006). This indicates that under normal conditions the neuroendocrine and immune systems coordinate to ensure maintenance of homeostasis. Indeed, patients with IBS show inadequately low concentration of the antiinflammatory steroid hormone, cortisol (Straub et al., 2002).

In conclusion, we assume that the intimate communication between the microbiota-immune-neuroendocrine systems involves multiple-functioning molecule(s). Those same molecule(s) appear to be produced by and signal member(s) of the gut microbial community, the neuroendocrine and immune systems to mount or avoid rising an attack response against the commensals. This would be of crucial importance early in life. During 
this vulnerable period, it is believed to exist a narrow window during which colonization with a "healthy" microbiota exerts effects that may decrease susceptibility to diseases and ensure normal development of the mucosal and systemic immunity and metabolism as well as the development of HPA axis,which impacts on the gut through its action on the enteric nervous system, immune system and the CNS (Sudo et al., 2004; Shreiner et al., 2008). The most important question needed to be answered at this point, what would be the molecular mechanisms underlying the intimate cross-talk between the immune system and the microbiota-gut-brain axis at its various nodes of interaction?

\section{REFERENCES}

Borovikova, L. V., Ivanova, S., Zhang, M., Yang, H., Botchkina, G. I., Watkins, L. R., et al. (2000). Vagus nerve stimulation attenuates the systemic inflammatory response to endotoxin. Nature 405 , 458-462. doi: $10.1038 / 35013070$

Campos-Rodríguez, R., Godínez-Victoria, M., Abarca-Rojano, E., Pacheco-Yépez, J., ReynaGarfias, H., Barbosa-Cabrera, R. E., et al. (2013). Stress modulates intestinal secretory immunoglobulin A. Front. Integr. Neurosci. 7:86. doi: $10.3389 /$ fnint. 2013.00086

Capuron, L., and Miller, A. H. (2004). Cytokines and psychopathology: lessons from interferonalpha. Biol. Psychiatry 56, 819-824. doi: 10.1016/j.biopsych.2004.02.009

Capuron, L., Ravaud, A., Miller, A. H., and Dantzer, R. (2004). Baseline mood and psychosocial characteristics of patients developing depressive sy.mptoms during interleukin-2 and/or interferon-alpha cancer therapy. Brain Behav. Immun. 18, 205-213. doi: 10.1016/j.bbi.2003.11.004

Carvalho, F. A., Aitken, J. D., Vijay-Kumar, M., and Gewirtz, A. T. (2012). Toll-like receptor-gut microbiota interactions: perturb at your own risk! Annu. Rev. Physiol. 74, 177-198. doi: 10.1146/annurevphysiol-020911-153330

Clarke, G., Grenham, S., Scully, P., Fitzgerald, P., Moloney, R. D., Shanahan, F., et al. (2013). The microbiome-gut-brain axis during early life regulates the hippocampal serotonergic system in a sexdependent manner. Mol. Psychiatry 18, 666-673. doi: $10.1038 / \mathrm{mp} .2012 .77$

Clarke, G., Quigley, E. M., Cryan, J. F., and Dinan, T. G. (2009). Irritable bowel syndrome: towards biomarker identification. Trends Mol. Med. 15, 478-489. doi: 10.1016/j.molmed.2009.08.001

Collins, S. M., and Bercik, P. (2013). Gut microbiota: intestinal bacteria influence brain activity in healthy humans. Nat. Rev. Gastroenterol. Hepatol. 10, 326-327. doi: 10.1038/nrgastro. 2013.76

Costello, E. K., Stagaman, K., Dethlefsen, L., Bohannanm, B. J., and Relman, D. A. (2012). The application of ecological theory toward an understanding of the human microbiome. Science 336, 1255-1262. doi: 10.1126/science. 1224203
Desbonnet, L., Clarke, G., Shanahan, F., Dinan, T. G., and Cryan, J. F. (2014). Microbiota is essential for social development in the mouse. Mol. Psychiatry 19, 146-148. doi: 10.1038/mp.2013.65

Diaz-Heijtz, R., Wang, S., Anuar, F., Qian, Y., Björkholm, B., Samuelsson, A., et al. (2011). Normal gut microbiota modulates brain development and behavior. Proc. Natl. Acad. Sci. U.S.A. 108, 3047-3052. doi: 10.1073/pnas.1010529108

Dinan, T. G., and Cryan, J. F. (2012). Regulation of the stress response by the gut microbiota: implications for psychoneuroendocrinology. Psychoneuroendocrinology 37, 1369-1378. doi: 10.1016/j.psyneuen.2012.03.007

Dominguez-Bello, M. G., Costello, E. K., Contreras, M., Magris, M., Hidalgo, G., Fierer, N., et al. (2010). Delivery mode shapes the acquisition and structure of the initial microbiota across multiple body habitats in newborns. Proc. Natl. Acad. Sci. U.S.A. 107, 11971-11975. doi: 10.1073/pnas.1002601107

El Aidy, S., Derrien, M., Aardema, R., Hooiveld, G., Richards, S. E., Dane, A., et al. (2013b). Transient inflammatory-like state and microbial dysbiosis are pivotal in establishment of mucosal homeostasis during colonisation of germ-free mice. Benef. Microbes 5, 67-77. doi: 10.3920/BM2013.0018

El Aidy, S., and Kleerebezem, M. (2013a). Molecular signatures for the dynamic process of establishing intestinal host-microbial homeostasis: potential for disease diagnostics? Curr. Opin. Gastroenterol. 29, 621-627. doi: 10.1097/MOG.0b013e328365d365

El Aidy, S., Kunze, W., Bienenstock, J., and Kleerebezem, M. (2012b). The microbiota and the gut-brain axis: insights from the temporal and spatial mucosal alterations during colonisation of the germfree mouse intestine. Benef. Microbes. 3, 251-259. doi: 10.3920/BM2012.0042

El Aidy, S., Merrifield, C. A., Derrien, M., van Baarlen, P., Hooiveld, G., Levenez, F., et al. (2013c). The gut microbiota elicits a profound metabolic reorientation in the mouse jejunal mucosa during conventionalisation. Gut 62, 1306-1314. doi: 10.1136/gutjnl-2011-301955

El Aidy, S., van Baarlen, P., Derrien, M., LindenberghKortleve, D. J., Hooiveld, G., Levenez, F., et al. (2012a). Temporal and spatial interplay of microbiota and intestinal mucosa drive establishment of immune homeostasis in conventionalized mice. Mucosal Immunol. 5, 567-579. doi: 10.1038/mi.2012.32

Felger, J. C., Li, L., Marvar, P. J., Woolwine, B. J., Harrison, D. G., Raison, C. L., et al. (2013). Tyrosine metabolism during interferon-alpha administration: association with fatigue and CSF dopamine concentrations. Brain Behav. Immun. 31, 153-160. doi: 10.1016/j.bbi.2012.10.010

Gevers, D., Kugathasan, S., Lee, D. A., Va'zquezBaeza, Y., Van Treuren, W., Ren, B., et al. (2014). The treatment-naive microbiome in new-onset Crohn's disease. Cell Host Microbe 15, 382-392. doi: 10.1016/j.chom.2014.02.005

Harbour-McMenamin, D., Smith, E. M., and Blalock, J. E. (1985). Bacterial lipopolysaccharide induction of leukocyte-derived corticotropin and endorphins. Infect. Immun. 48, 813-817.

Hollis, J. H., Evans, A. K., Bruce, K. P., Lightman, S. L., and Lowry, C. A. (2006). Lipopolysaccharide has indomethacin-sensitive actions on Fos expression in topographically organized subpopulations of serotonergic neurons. Brain Behav. Immun. 20, 569-577. doi: 10.1016/j.bbi.2006.01.006

Hooper, L. V., Littman, D. R., and Macpherson, A. J. (2012). Interactions between the microbiota and the immune system. Science 336, 1268-1273. doi: $10.1126 /$ science. 1223490

Lemon, K. P., Armitage, G. C., Relman, D. A., and Fischbach, M. A. (2012). Microbiota-targeted therapies: an ecological perspective. Sci. Transl. Med. 4, 137rv5. doi: 10.1126/scitranslmed.3004183

Lowry, C.A., Hollis, J. H., de Vries, A., Pan, B., Brunet, L. R., Hunt, J. R., et al. (2007). Identification of an immune-responsive mesolimbocortical serotonergic system: potential role in regulation of emotional behavior. Neuroscience 146, 756-772. doi: 10.1016/j.neuroscience.2007.01.067

Lyte, M. (2011). Probiotics function mechanistically as delivery vehicles for neuroactive compounds: microbial endocrinology in the design and use of probiotics. Bioessays 33, 574-581. doi: 10.1002/bies.201100024

Maestroni, G. J. (2000). Dendritic cell migration controlled by alpha $1 \mathrm{~b}$-adrenergic receptors. J. Immunol. 165, 6743-6747.

Magro, F., Vieira-Coelho, M. A., Fraga, S., Serrão, M. P., Veloso, F. T., Ribeiro, T., et al. (2002). Impaired synthesis or cellular storage of norepinephrine, dopamine, and 5-hydroxytryptamine in human inflammatory bowel disease. Dig. Dis. Sci. 47, 216-224. doi: 10.1023/A:1013256 629600

Maier, S. F., Goehler, L. E., Fleshner, M., and Watkins, L. R. (1998). The role of the vagus nerve in cytokine-to-brain communication. Ann. N.Y. Acad. Sci. 840, 289-300. doi: 10.1111/j.17496632.1998.tb09569.x

Miller, L. E., Weidler, C., Falk, W., Angele, P., Schaumburger, J., Schölmerich, J., et al. (2004). Increased prevalence of semaphorin $3 \mathrm{C}$, a repellent of sympathetic nerve fibers, in the synovial tissue of patients with rheumatoid arthritis. Arthritis Rheum. 50, 1156-1163. doi: 10.1002/art. 20110

Moffett, J. R., and Namboodiri, M. A. (2003). Tryptophan and the immune response. Immunol. Cell Biol. 81, 247-265. doi: 10.1046/j.1440-1711.2003.t01-1-01177.x

Moloney, R. D., Desbonnet, L., Clarke, G., Dinan, T. G., and Cryan, J. F. (2014). The microbiome: stress, health and disease. Mamm. Genome 25, 49-74. doi: 10.1007/s00335-013-9488-5

Neufeld, K. M., Kang, N., Bienenstock, J., and Foster, J. A. (2011). Reduced anxiety-like behavior and central neurochemical change in germ-free mice. Neurogastroenterol. Motil. 23, 255-264, e119. doi: 10.1111/j.1365-2982.2010.01620.x

Pert, C. B., Ruff, M. R., Weber, R. J., and Herkenham, M. (1985). Neuropeptides and their receptors: a psychosomatic network. J. Immunol. 135, 820s-826s.

Raison, C. L., Rutherford, R. E., Woolwine, B. J., Shuo, C., Schettler, P., Drake, D. F., et al. (2013). A randomized controlled trial of the tumor necrosis factor antagonist infliximab for treatmentresistant depression: the role of baseline inflammatory biomarkers. JAMA Psychiatry 70, 31-41. doi: 10.1001/2013.jamapsychiatry.4 
Reardon, C., Duncan, G. S., Brüstle, A., Brenner, D., Tusche, M. W., Olofsson, P. S., et al. (2013). Lymphocyte-derived ACh regulates local innate but not adaptive immunity. Proc. Natl. Acad. Sci. U.S.A. 110, 1410-1415. doi: 10.1073/pnas.1221 655110

Roshchina, V. V. (2010). "Evolutionary considerations of neurotransmitters in microbial, plant, and animal cells," in Microbial Endocrinology: Interkingdom Signaling in Infectious Diseases and Health, eds M. Lyte and P. P. E. Freestone (New York, NY: Springer), 17-52. doi: 10.1007/978-14419-5576-0_2

Rühl, A., and Collins, S. M. (1997). Role of nitric oxide in norepinephrine release from myenteric plexus in vitro and in Trichinella spiralis-infected rats. Neurogastroenterol. Motil. 9, 33-39. doi: 10.1046/j.1365-2982.1997.d01-5.x

Rühl, A., Hurst, S., and Collins, S. M. (1994). Synergism between interleukins 1 beta and 6 on noradrenergic nerves in rat myenteric plexus. Gastroenterology 107, 993-1001.

Shreiner, A., Huffnagle, G. B., and Noverr, M. C. (2008). "The "microflora hypothesis" of allergic disease," in GI Microbiota and Regulation of the Immune System, eds G. B. Huffnagle and M. C. Noverr (Landes Bioscience and Springer Science + Business Media), 113-34. doi: 10.1007/978-0-38709550-9_10
Spengler, R. N., Allen, R. M., Remick, D. G., Strieter, R. M., and Kunkel, S. L. (1990). Stimulation of alpha-adrenergic receptor augments the production of macrophagederived tumor necrosis factor. J. Immunol. 145 , 1430-1434.

Steinman, L. (2004). Elaborate interactions between the immune and nervous systems. Nat. Immunol. 5, 575-581. doi: 10.1038/ni1078

Sternberg, E. M. (1997). Neural-immune interactions in health and disease. J. Clin. Invest. 100, 2641-2647. doi: 10.1172/JCI119807

Straub, R. H., Günzler, C., Miller, L. E., Cutolo, M., Schölmerich, J., and Schill, S. (2002). Antiinflammatory cooperativity of corticosteroids and norepinephrine in rheumatoid arthritis synovial tissue in vivo and in vitro. FASEB J. 16, 993-1000. doi: 10.1096/fj.02-0085com

Straub, R. H., Wiest, R., Strauch, U. G., Härle, P., and Schölmerich, J. (2006). The role of the sympathetic nervous system in intestinal inflammation. Gut 55, 1640-1649. doi: 10.1136/gut.2006. 091322

Sudo, N., Chida, Y., Aiba, Y., Sonoda, J., Oyama, N., Yu, X. N., et al. (2004). Postnatal microbial colonization programs the hypothalamicpituitary-adrenal system for stress response in mice. J. Physiol. 558, 263-275. doi: 10.1113/jphysiol.2004.063388
Wang, Y., and Kasper, L. H. (2013). The role of microbiome in central nervous system disorders. Brain. Behav. Immun. doi: 10.1016/j.bbi.2013.12.015. [Epub ahead of print].

Conflict of Interest Statement: The authors declare that the research was conducted in the absence of any commercial or financial relationships that could be construed as a potential conflict of interest.

Received: 16 March 2014; accepted: 20 March 2014; published online: 07 April 2014.

Citation: El Aidy S, Dinan TG and Cryan JF (2014) Immune modulation of the brain-gut-microbe axis. Front. Microbiol. 5:146. doi: 10.3389/fmicb.2014.00146 This article was submitted to Evolutionary and Genomic Microbiology, a section of the journal Frontiers in Microbiology.

Copyright () 2014 El Aidy, Dinan and Cryan. This is an open-access article distributed under the terms of the Creative Commons Attribution License (CC BY). The use, distribution or reproduction in other forums is permitted, provided the original author(s) or licensor are credited and that the original publication in this journal is cited, in accordance with accepted academic practice. No use, distribution or reproduction is permitted which does not comply with these terms. 